\title{
Winter mortality, development and reproduction in a field population of Myzus persicae (Sulzer) (Hemiptera: Aphididae) in England
}

\author{
R. HARRINGTON \\ Department of Entomology, Rothamsted Experimental Station, Harpenden, Hertfordshire, AL5 2JQ, \\ $U K$
}

Cheng Xia-Nian

Department of Plant Protection, Nanjing Agricultural College, Nanjing, China

\begin{abstract}
Population change in Myzus persicae (Sulz.) overwintering on spring cabbage in south-eastern England was studied in relation to meteorological and biological factors. Leaf surface wetness and temperature were correlated significantly with rate of population change, but rainfall and wind were not. Growth and development continued slowly throughout the winter, and the relationship with temperature is shown. Hymenopterous parasites, the fungus Entomophthora and predatory spiders did not affect winter survival.
\end{abstract}

\section{Introduction}

Myzus persicae (Sulzer) is largely anholocyclic in England (Broadbent \& Heathcote, 1955). Winter conditions thus have an important influence on survival and on the timing and size of spring flight. Watson et al. (1975) found a relationship between virus incidence in sugarbeet in August and temperature during the previous January-April, and assumed the aphid vector to be the link between the two without actually investigating the effect of temperature on the aphid's winter survival. Taylor (1977) showed that $M$. persicae overwinters more successfully in the south-east of England than in the west and suggested that some function of precipitation as well as low temperature might limit survival. In the present paper, the effect of various meteorological and biological conditions on mortality, development and reproduction of individuals in a population of $M$. persicae overwintering on spring cabbages in south-eastern England is examined quantitatively.

\section{Methods}

The work was done during the winters of 1981-82 and 1982-83 on a farm at Broom, Bedfordshire (grid reference TL166427, altitude $40 \mathrm{~m}$ ), which is in an exposed position on the Bedfordshire plain. Spring cabbage (cv. Durham Early) was sampled from adjacent fields in the two winters. In 1981-82, the crop was drilled on 20 August and cut during April and early May; in 1982-83, the crop was drilled in mid-August and cut during late April, May and early June.

\section{Weather recording}

A nine-channel paper-chart thermograph recorded temperature hourly on the underside of an old south-facing leaf and an old north-facing leaf, and inside a Perspex clip cage 
on the underside of an old south-facing leaf. Green bead thermistors $2 \mathrm{~mm}$ in diameter (resembling adult apterae of $M$. persicae in size and colour) were used for sensing the temperatures.

Rainfall was recorded using a tilting-siphon rain gauge (Meteorological Office, 1982) with a continuous chart record of amount and duration of precipitation. A standard $12.5 \mathrm{~cm}(5$-in.) rain gauge comprising a fibreglass funnel leading into a bottle was used to collect precipitation as a check.

Leaf surface wetness was recorded using a Meteorological Office mark 3 wetness recorder (Hirst, 1957). Wind speed and direction were recorded continuously on a paper chart using a Woelfle anemometer at $1 \mathrm{~m}$. Sunshine records were taken from Rothamsted Experimental Station, $40 \mathrm{~km}$ south of the sampling site.

\section{Monitoring changes in aphid numbers}

In order to observe fluctuations in size of population of $M$. persicae, 12 plants were selected in 1981-82 and 20 plants in 1982-83 for monitoring at approximately weekly intervals. From early October, as the weather allowed, aphids were counted on all leaves after carefully raising them individually. The time of abscission of each leaf was noted. The numbers of aphids mummified by parasitic Hymenoptera and killed by the fungus Entomophthora, as well as the numbers of predacious spiders found on the plants, were noted in 1982-83.

To examine the effect of weather on the rate of population change, the daily rates of change, $\left(\log N_{2}-\log N_{1}\right) / t$ (where $N_{1}$ and $N_{2}$ are the number of aphids present in first and second observations, respectively, of each consecutive pair and $t$ is the number of days between samples), either positive (an increase in the number of aphids between samples) or negative (a fall), were regressed on mean weather values recorded between samples, using simple linear regression analysis. Multiple regressions were used to examine the interactions of the factors. Rate of leaf fall was also examined as a potential factor contributing to rate of change of the population. After a spell of extreme low temperature in January 1982, the density of aphids became exceedingly low. When $N_{1}$ fell below 1 aphid per plant, the sample was not included in the regression analysis.

\section{Monitoring development and reproduction}

On each visit in 1982-83, aphid individuals or colonies were selected and enclosed within each of 25 cages. Different plants were used from those on which aphid numbers were monitored. Some of the colonies were used to observe development and some to observe reproduction. The cages (Honeyborne, 1969) covered an area of $3 \cdot 15 \mathrm{~cm}^{2}$ and comprised two plastic cylinders $2 \mathrm{~cm}$ in diameter and $1.25 \mathrm{~cm}^{2}$ high, one on each side of a spring clip. The rim of each cylinder was covered with a thin layer of sponge which rested on the leaf. One cylinder rested on each leaf surface, aphid colonies being confined on the lower surface. The tops of both of the cylinders were open.

Those colonies used to record development comprised 1-10 nymphs. The instar of each nymph was recorded on two successive visits. The number of moults per surviving individual could then be calculated for each pair of observations. Any aphids which had died between visits were excluded from the calculations, and if there was any uncertainty about the identity of an individual aphid on the second observation (sometimes the case when aphids of different instars were in the same cage at the first observation), these aphids were also excluded from the calculation if any of the original aphids had died.

Similarly, single adult apterae were caged to observe reproduction. The number of nymphs produced per adult between each pair of observations was calculated. If adults died between observations, the nymphs produced were not included in the calculation.

If the leaves remained in good condition on the second visit, the aphids on them were sometimes used to form the first observation of the next pair. New colonies were found to make the total number of ' initial' cages up to 25 .

To examine the effect of temperature on aphid development and reproduction, the 
rates of moulting and of parturition were regressed on mean temperature between observations using simple linear regression.

\section{Results}

The progress of the population with time is shown for each winter in Fig. 1.

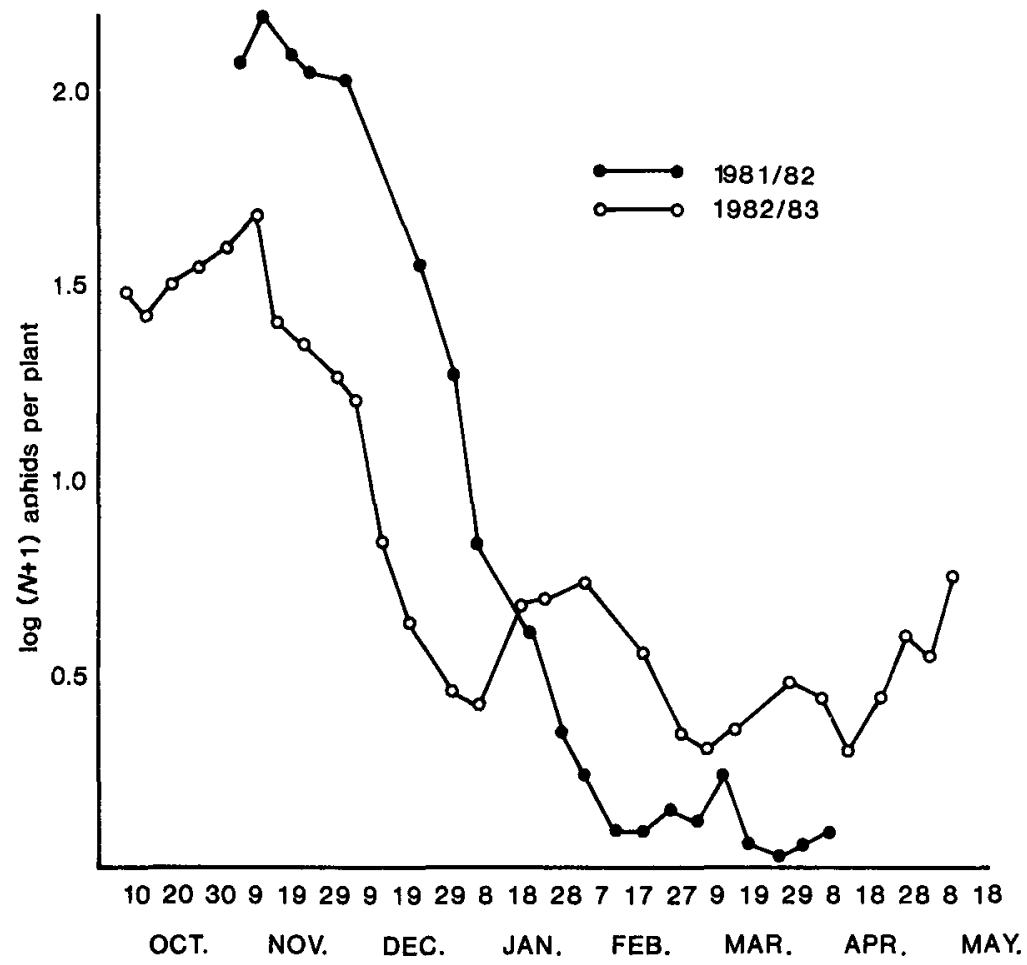

Fig. 1. - Variation in log total number of $M$. persicae per plant with time in $1981-82$ and $1982-83$.

TABLE I. Coefficients of correlation (r) between daily rate of change in aphid numbers and weather $(\mathrm{n}=35)$

\begin{tabular}{|c|c|c|c|c|c|c|}
\hline \multirow{7}{*}{$\begin{array}{l}\text { Mean } \\
\text { temperature } \\
\text { Mean wetness } \\
\text { duration } \\
\text { Mean } \\
\text { rainfall } \\
\text { Mean } \\
\text { windspeed } \\
\text { Mean } \\
\text { sunshine } \\
\text { Rate of } \\
\text { leaf fall }\end{array}$} & $\frac{\log N_{2}-\log N_{1}}{t}$ & $\begin{array}{c}\text { Mean } \\
\text { temperature }\end{array}$ & $\begin{array}{l}\text { Mean wetness } \\
\text { duration }\end{array}$ & $\begin{array}{l}\text { Mean } \\
\text { rainfall }\end{array}$ & $\begin{array}{l}\text { Mean wind } \\
\text { speed }\end{array}$ & $\begin{array}{l}\text { Mean } \\
\text { sunshine }\end{array}$ \\
\hline & $0.4123^{*}$ & & & & & \\
\hline & $-0.4451^{* *}$ & -0.3290 & & & & \\
\hline & -0.2836 & 0.2543 & $0.3425^{*}$ & & & \\
\hline & $0 \cdot 1682$ & 0.1082 & $-0.3477^{*}$ & 0.0896 & & \\
\hline & 0.3188 & 0.1258 & -0.2075 & $0 \cdot 3274$ & -0.0426 & \\
\hline & $0 \cdot 3651^{*}$ & $0.6406^{* * *}$ & $-0.3350^{*}$ & $0 \cdot 2690$ & 0.0211 & $0.4573^{* *}$ \\
\hline $\begin{array}{l}N_{1}, N_{1}=\mathrm{nc} \\
t=\text { no. of d } \\
* P<0.05 \\
* P<0.01 \\
* * P<0.00\end{array}$ & $\begin{array}{l}\text { ids present on fir } \\
\text { reen observations }\end{array}$ & $\begin{array}{l}\text { st and second } \\
\text { s. }\end{array}$ & bservations of & & & \\
\hline
\end{tabular}


The effect of weather factors on rate of population change

The daily rate of change of total aphid numbers was positively and linearly related to mean temperature (from the underside of an old north-facing and an old south-facing leaf) $(P<0.05)$ (Fig. 2a) and negatively related to mean leaf surface wetness $(P<0.01)($ Fig. $2 b)$,
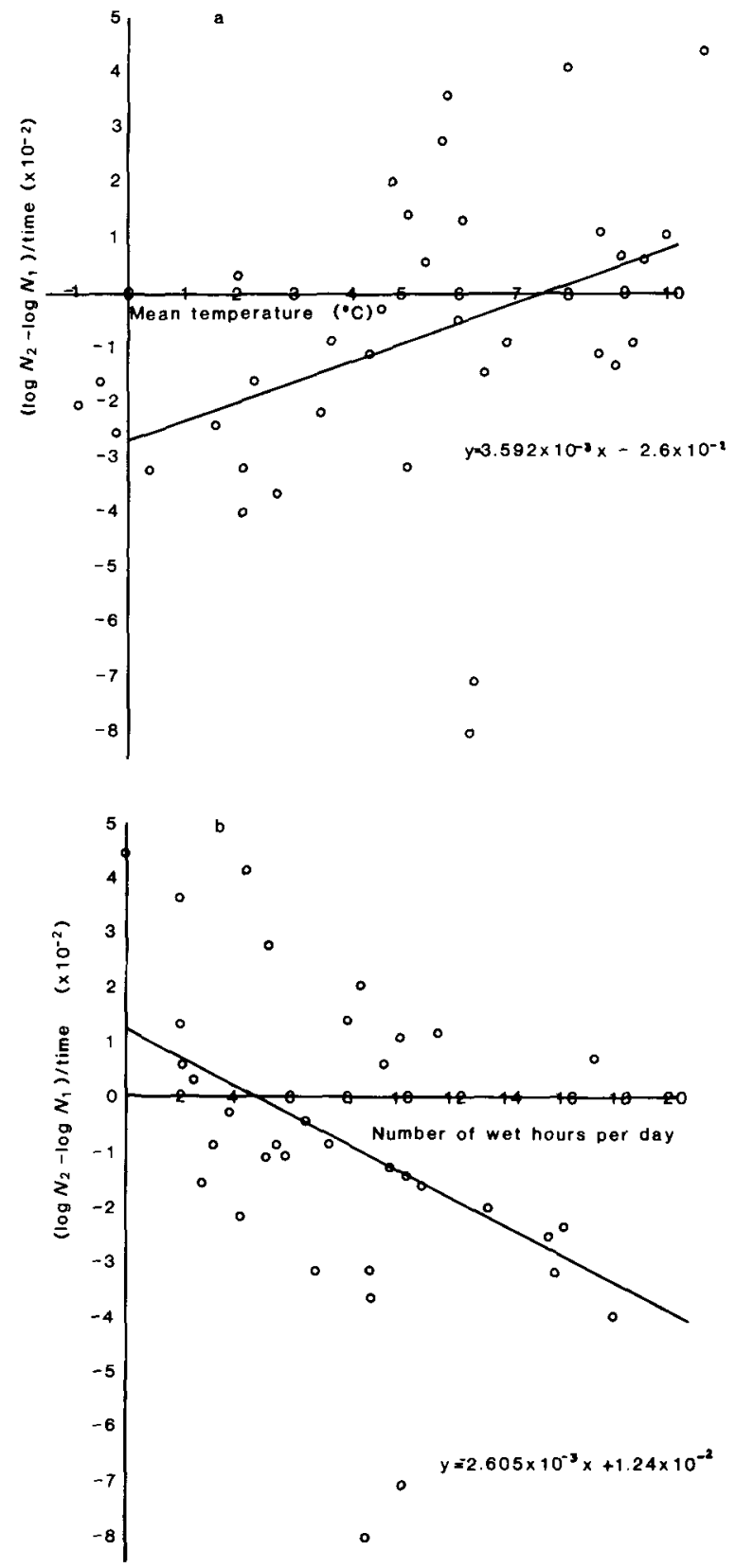

Fig. 2a. - Rate of change of numbers of $M$. persicae with temperature. $2 b$.- Rate of change of numbers of $M$. persicae with leaf surface wetness. 
but not significantly related to mean rainfall, wind speed or amount of sunshine (Table I). The rate of leaf fall was positively correlated with temperature $(P<0 \cdot 05)$.

Temperature and surface wetness accounted for $23 \%$ of the variance in rate of population change (Table II). Temperature, rain, wind and sun accounted for $47 \%$. These factors combined to affect surface wetness and except for temperature were not significant when considered alone.

TABLE II. Percentage of variance accounted for in simple and multiple regressions of daily rate of change of total aphid numbers on weather parameters

Weather parameter(s)

Mean temperature $(T)$

Mean duration of leaf surface wetness $(W)$

Mean rainfall $(R)$

Mean wind velocity $(V)$

Mean duration of sunshine $(S)$

Mean rate of leaf fall $(F)$

$T W$

TR

$T S$

TF

WR

TWRS

TWVS

TRVS

TWSRV

TWSRVF
$\%$ variance accounted for

$14 \cdot 48$

$17 \cdot 38$

$5 \cdot 25$

$-0 \cdot 11$

$7 \cdot 44$

$10 \cdot 70$

$23 \cdot 22$

$28 \cdot 94$

$19 \cdot 50$

$13 \cdot 65$

$29 \cdot 41$

$43 \cdot 52$

$23 \cdot 52$

$47 \cdot 38$

$46 \cdot 73$

$44 \cdot 85$

\section{The effect of weather factors on development and reproduction}

Development and reproduction of caged aphids continued at a slow rate throughout the winter. The number of moults per surviving individual and the number of births per surviving adult were linearly correlated with temperature (recorded inside a clip cage) $(P<0.001)$ (Fig. 3). Over the whole period of observation, the temperature inside the cages averaged $0.05^{\circ} \mathrm{C}$ lower than the temperature outside.

\section{Effect of natural enemies on winter survival}

Hymenopterous parasites and Entomophthora spp. had no important effect on winter survival of $M$. persicae. The number of aphids mummified by Diaeretiella rapae (M'Intosh) or Ephedrus plagiator (Nees) on 20 plants was at a maximum between 19 October and 15 November, but the proportion at this time was only 1-2\%. The number of aphids infected by Entomophthora peaked in early November, but the proportion only reached $2 \cdot 6 \%$. Very little new infection was seen after mid-December, and old mummies and fungus-infected bodies remained until leaves fell.

Predacious spiders are unlikely to have an important effect on overwintering survival of $M$. persicae on spring cabbage. The density of spiders was at a maximum of 0.16 per plant (including the surrounding soil) between mid-October and late November. Most of these were the small-bodied species Erigone atra Blackwall and Lepthyphantes tenuis (Blackwall). In experimental chambers at $11^{\circ} \mathrm{C}$, their consumption was only 0.5 aphid per week for females and $0 \cdot 1$ for males.

\section{Discussion}

The suggestions of Watson et al. (1975) and Taylor (1977) that the overwintering success of $\boldsymbol{M}$. persicae is likely to be dependent on functions of temperature and precipitation have been borne out by the field observations in this study. However, rainfall in itself was not well correlated with rate of population change, and temperatures above those which might be expected to cause death by freezing (Adams, 1962) appeared to affect survival. It is thus of interest to consider the effects of the meteorological conditions on mortality. 

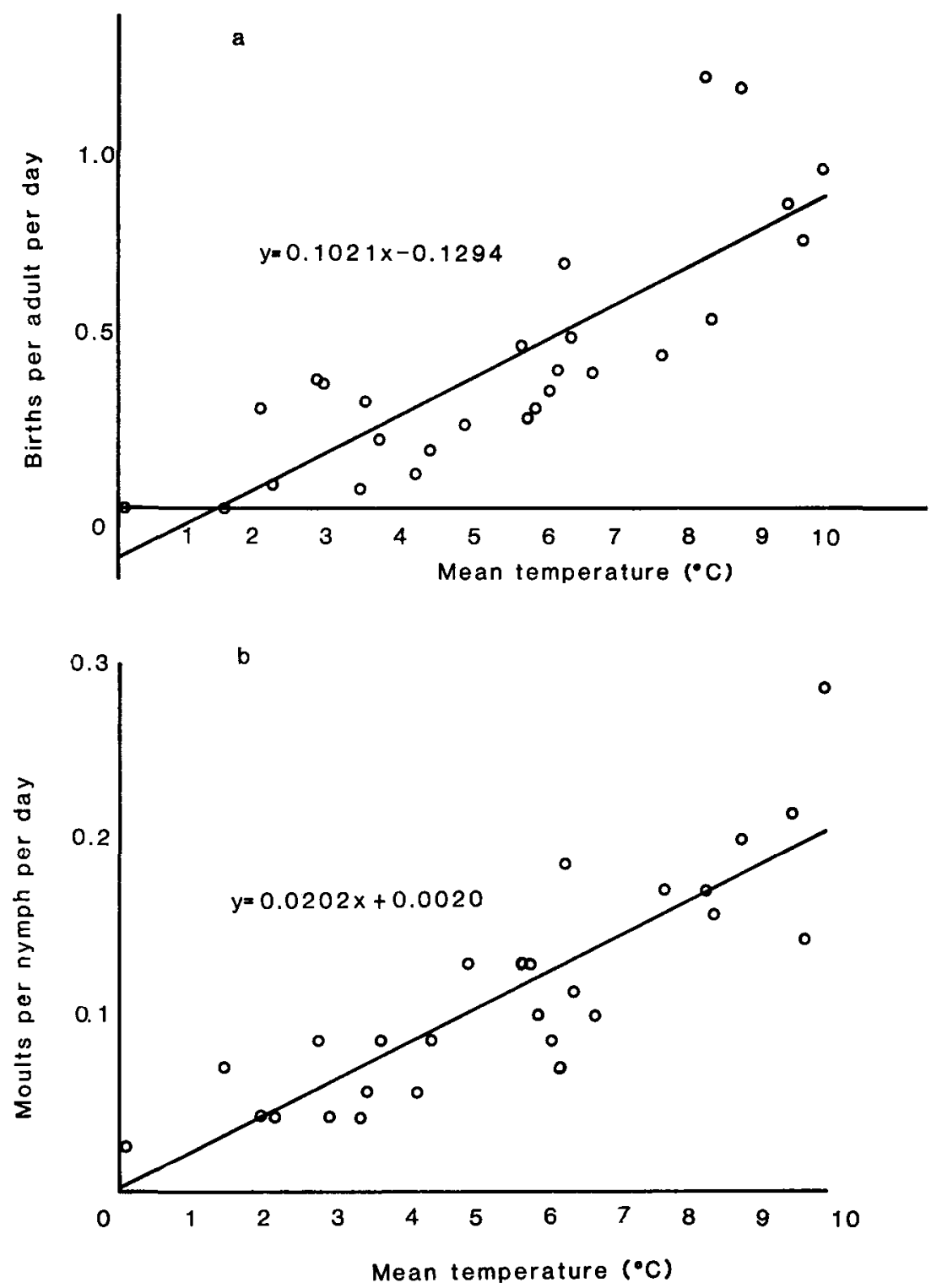

Fig. 3a.-The number of $M$. persicae births per adult per day in clip cages plotted against temperature. $3 b$. - The number of $M$. persicae moults per nymph per day in clip cages plotted against temperature.

$M$. persicae colonises preferentially the older leaves of spring cabbages which fall throughout the winter (Harrington, 1984). This observation leads to the expectation that factors which prevent or impede movement would be related to mortality. While a senescing leaf remains attached to the plant, an aphid has only a short journey from the base of the old leaf to the base of a younger leaf within a relatively well protected part of the plant, whereas once the leaf has fallen, a far longer and more hazardous journey is necessary. In sufficiently warm and dry conditions, aphids can respond to leaf senescence 
by moving to a younger leaf before the older leaf falls. However, if the period of senescence to which the aphid can respond occurs during a time of high surface wetness or low temperature, either of which will hinder movement, then the aphid may be forced to remain on the leaf until after it has fallen, significantly lowering its chance of survival. The threshold temperatures for movement are higher than the thermal death point, and the effective thresholds for survival are hence raised. For example, Smith (1981) working with Sitobion avenae ( $\mathrm{F}$.) found that at $3^{\circ} \mathrm{C}$ all were capable of movement. At $-1^{\circ} \mathrm{C}$, no first instars could move and at $-4^{\circ} \mathrm{C}$ no aphids could move at all. Aitchison (1978) found some aphids in Manitoba to be 'winter active' down to temperatures of $-5.5^{\circ} \mathrm{C}$. At $-3^{\circ} \mathrm{C}$, Adams (1962) found that $50 \%$ of $M$. persicae tested were still alive after $600 \mathrm{~h}$. At $-12^{\circ} \mathrm{C}$, $1 \%$ were still alive after $4 \mathrm{~h}$. Parry (1978) showed that unfed first instars of $M$. persicae could be supercooled to $-20^{\circ} \mathrm{C}$ before freezing. Thus at temperatures which completely immobilise aphids, little mortality is caused directly. Under extreme weather conditions, a direct effect on mortality can be expected, and this certainly occurred during the cold December and January of 1981-82 when several dead aphids were found hanging from leaves with stylets still inserted.

Rainfall was not correlated strongly with population change, probably because the aphids near the base of the leaves are relatively well protected from its direct effect.

Complex interactions exist amongst the weather parameters (Table I) which make the interpretation of the multiple regression analyses difficult. The regression itself is a reflection of individual thresholds as well as continuous functional relationships (Taylor, 1963). Also, for example, the degree of surface wetness results from the effect of frost and dew, which are related negatively to temperature, as well as from the obvious effect of rainfall and from wind which has a drying effect. Temperature, surface wetness, rain, wind and sun together accounted for $47 \%$ of the variance in rate of population change in a multiple regression, but removing wetness from this made no difference (Table II); $48 \%$ of the variance was accounted for in a multiple regression of surface wetness on temperature, rainfall, wind and sun. Similarly, the rate of population change was positively correlated with rate of leaf fall, but the latter was strongly related to temperature and its significance is lost in a multiple regression including temperature.

It was not practicable to sample more regularly than about once a week, although daily fluctuations in weather conditions are likely to have considerable influence on the rate of change in population size. Considerably more variance in the rate of change of the population could probably have been explained had more regular sampling been feasible.

These biological data back up prior speculations on the effect of winter conditions on the survival of $\boldsymbol{M}$. persicae. A thorough understanding of the overwintering biology of the aphid is an essential prerequisite for forecasting its importance in virus spread and the need for its control.

\section{Acknowledgements}

X. N. Cheng acknowledges support from the Chinese Ministry of Education in allowing funding and leave to work in the UK.

We thank Dr L. R. Taylor (Rothamsted Insect Survey) for guidance, Dr C. Hume (Meteorological Office) for advice and equipment, and Mr R. J. Capon (West End Farm) for co-operation. The work was funded by a grant from the Potato Marketing Board which is gratefully acknowledged.

\section{References}

ADams, J. B. (1962). Aphid survival at low temperatures.-Can. J. Zool. 40, 951-956.

AIrchison, C. W. (1978). Notes on low temperature and winter activity of Homoptera in Manitoba.-Manitoba Entomol. 12, 58-60.

Broadbent, L. \& Heathcote, G. D. (1955). Sources of overwintering Myzus persicae (Sulzer) in England.-Pl. Path. 4, 135-137. 
Harrington, R. (1984). The effect of weather and behaviour on the winter survival of $M y z u s$ persicae.-Potato Res. 27, 105.

Hirst, J. M. (1957). A simplified surface-wetness recorder.-Pl. Path. 6, 57-61.

Honeyborne, C. H. B. (1969). An investigation of the response of aphids to plants treated with growth regulators. $-252 \mathrm{pp}$. Ph.D. thesis, Univ. Reading.

Meteorological OfFice (1982). Observers' handbook.-4th edn, 220 pp. London, H.M.S.O.

PARRY, W. H. (1978). Supercooling of Myzus persicae in relation to gut content.-Ann. appl. Biol. 90, 27-34.

Smrth, R. K. (1981). Studies on the ecology of cereal aphids and prospects for integrated control.-400 pp. Ph.D. thesis, Univ. London.

TAYlor, L. R. (1963). Analysis of the effect of temperature on insects in flight.-J. Anim. Ecol. 32, 99-117.

TAYlor, L. R. (1977). Migration and the spatial dynamics of an aphid, Myzus persicae.-J. Anim. Ecol. 46, 411-423.

Watson, M. A., Heathcote, G. D., Lauckner, F. B. \& Sowray, P. A. (1975). The use of weather data and counts of aphids in the field to predict the incidence of yellowing viruses of sugar-beet crops in England in relation to the use of insecticides.-Ann. appl. Biol. 81, 181-198.

(Received 16 March, revised 24 April 1984)

(C) Commonwealth Agricultural Bureaux, 1984 